\title{
Chaotic Discrimination and Non-Linear Dynamics
}

\author{
Partha Gangopadhyay \\ School of Economics and Finance, University of Western Sydney \\ Locked Bag 1791, Penrith South DC, NSW 1791, Australia
}

\begin{abstract}
This study examines a particular form of price discrimination, known as chaotic discrimination, which has the following features: sellers quote a common price but, in reality, they engage in secret and apparently unsystematic price discounts. It is widely held that such forms of price discrimination are seriously inconsistent with profit maximization by sellers.. However, there is no theoretical salience to support this kind of price discrimination. By straining the logic of non-linear dynamics this study explains why such secret discounts are chaotic in the sense that sellers fail to adopt profit-maximising price discounts. A model is developed to argue that such forms of discrimination may derive from the regions of instability of a dynamic model of price discounts.
\end{abstract}

Key words: Nash Equilibrium, Price Discrimination, Fixed Points, Stability

\section{INTRODUCTION}

Joseph Bain offers examples of various forms of price discrimination as arbitrary and non-profit maximizing and therefore labels them as purely unpredictable. He calls these forms of price discrimination 'chaotic' [1]. Price discrimination is chaotic since it does not conform to profit maximization and as a result this form of pricing does not constitute an equilibrium in the Nash sense [2]. Since these prices do not form a Nash equilibrium there remains scope for sellers to unilaterally enhance their individual profits. Yet sellers fail to do so. The market is beset with a non-equilibrium and inefficient outcome. The precise aim of the present study is to apply the recent developments in non-linear and deterministic dynamic system to explain chaotic discrimination. Despite being an important component of industrial economics [3], this is the first attempt to explain chaotic discrimination in terms of a cohesive model.

During the last three decades the discovery of chaotic dynamics in simple non-linear deterministic systems has been a milestone in scientific research. The issue at stake is that even though all time paths of a deterministic dynamic system are bounded, trajectories that start close together diverge, or separate, exponentially. A significant import of chaotic behavior is that a precise prediction in deterministic models is not possible. Deterministic models can thus display fundamental randomness. A gradual collection of information does not remove this randomness nor makes prediction feasible. For economics science the study of chaotic behavior assumes great significance since the core of deductive equilibrium approach relies on a mutual consistency and fulfillment of expectations, or predictions, of agents. Typically, industrial economists focus their attention on economic models with regions of local stability on the assumption that regions of instability are of little importance and more of a pathological case [4]. The fundamental argument is that industrial economics does not find exploding time paths of any significant variable. However, the development of chaotic behavior significantly undermines this dismissal of regions of instability that can actually generate complex, yet deterministic, dynamics within bounds. The meeting point between chaotic dynamics and chaotic discrimination is the common feature of non-equilibrium behavior.

Bain [1] identified two principal forms of price discrimination as chaotic discrimination. The fundamental characteristic of such discrimination, he argued, embodies an element of irrationality in pricing decision. As a result such prices are believed to be arbitrary and non-profit-maximizing [1]. The first form is popular as the Basing-Point Pricing. Many goods are sold at delivered prices, which are the factory prices plus shipping mark-ups while sellers are disparately located. Every seller quotes a delivered price at a delivery point that equals the base price of the nearest seller plus the shipping mark-up from the nearest seller. As a result, price discrimination may emerge if buyers do not buy from the nearest seller. Such a form of discrimination is labeled as chaotic since the delivered prices are inconsistent with joint-profit maximization. Such a scheme of pricing evolved between 1880s and 1949 in cement, steel and certain other industries but after 1949 it gradually declined [3].

The second type of chaotic discrimination emerges when sellers quote a common price but secretly engage in arbitrary price discounts. As a result, different buyers pay different prices. Such price discrimination, Bain [1] argued, does not conform to a pattern of joint profit maximization and, hence, is arbitrary and non-profitmaximizing. Bain [1] rationalized such discrimination as an effort by oligopolists to avoid an open price war. In his opinion, there may exist a uniform pricing rule that would engender higher individual as well as joint profits. 
Yet the chaotic price discrimination is omnipresent in modern markets. What we understand is that this form of discrimination may not be underpinned by instrumental rationality of sellers and may not be an equilibrium phenomenon. This scheme of pricing, hence, came to be termed as chaotic discrimination that embodies a systematic departure from a profit-maximizing equilibrium pattern.

This form of chaotic discrimination is an important element of modern markets, but what causes it remains unclear. The explanation of Bain is inadequate for two reasons: first, we do not understand why sellers fail to arrive at an efficient equilibrium confirming conjectures/predictions of each of others' price discounts. Secondly, we know very little about the forces that stop sellers from secretly making Pareto improving price discounts and converge on a Nash equilibrium. The main purpose of this study is to address the second form of chaotic discrimination to answer these questions. A stylized case of chaotic discrimination was considered: the incumbent sellers choose a common posted price, but they engage in 'secret' price discounts from the posted price. We develop a model to argue that such discrimination may derive from the regions of instability of a dynamic model of price discounts.

The Model: We consider the classic case of duopoly in which two sellers compete against each other. A duopoly is the earliest model of game economists developed in the $18^{\text {th }}$ century to analyze interactive decision-making. The model can easily be extended to a n-person game [5]. In this model the strategic variable is price discounts. Each firm simultaneously chooses a price discount that impinges on own and rival profits. A price discount by seller $i$ affects the number of customers of seller $j$ (cross effect) while the own price effect works through the individual and downward sloped demand function. Let us now characterize the game:

Assumption 1: We write the revenue function of the $\mathrm{i}^{\text {th }}$ seller as the following:

$\mathrm{R}_{\mathrm{i}}=\mathrm{M}_{\mathrm{i}} \chi\left(\mathrm{P}^{\mathrm{D}}-\Delta \mathrm{P}_{\mathrm{i}}\right)$

Where, $\mathrm{M}_{\mathrm{i}}$ is the number of customers who purchase from seller $\mathrm{i}$ and $\chi$ is the demand function of each customer. $\Delta \mathrm{P}_{\mathrm{i}}$ is the price discount undertaken by seller $\mathrm{i}$, $\mathrm{P}^{\mathrm{D}}$ is the posted price. This assumption about the revenue function comes from Stiglitz [6].

Assumption 2: We also assume the following:

$\mathrm{M}_{\mathrm{i}}=\alpha\left(\mathrm{P}^{\mathrm{D}}-\Delta \mathrm{P}_{\mathrm{j}}\right)$

$\chi=\beta_{1}-\beta_{2}\left(\mathrm{P}^{\mathrm{D}}-\Delta \mathrm{P}_{\mathrm{i}}\right)$

Once again it follows Stiglitz [6]. The general restriction is that $\left.\delta \mathrm{M}_{\mathrm{i}} / \delta \Delta \mathrm{P}_{\mathrm{j}}<0, \delta \chi / \delta \Delta \mathrm{P}_{\mathrm{i}}\right)>0$. The implicit assumption of (1b) is that buyers obtain information through 'wordof-mouth' that will allow each seller to maintain different price for a finite span [7]. Note that (1c) is the usual downward-sloped demand function.

The profit function of seller $\mathrm{i}, \Pi_{\mathrm{i}}$, reduces to the following:

$\mathrm{R}_{\mathrm{i}}=\alpha\left(\mathrm{P}^{\mathrm{D}}-\Delta \mathrm{P}_{\mathrm{j}}\right)\left[\beta^{1} \mathrm{P}^{\mathrm{D}}+\left(\beta_{2}-\beta^{1}\right) \Delta \mathrm{P}_{\mathrm{i}}-\beta_{2} \Delta \mathrm{P}_{\mathrm{i}}^{2}\right]$

Where:

$\beta^{1}==\beta_{1}-\beta_{2} P^{D}$

For the sake of simplification, we assume-without any loss of analytical bite- the cost of production is assumed to be zero.

Assumption 3: At date $t+1$ seller i makes incremental changes in the price discount as:

$\Delta \mathrm{P}_{\mathrm{i}}(\mathrm{t}+1)=\Delta \mathrm{P}_{\mathrm{i}}(\mathrm{t})+\mathrm{H}_{\mathrm{i}}\left[\delta \Pi_{\mathrm{i}}(\mathrm{t}) / \delta \Delta \mathrm{P}_{\mathrm{i}}(\mathrm{t})\right]$

$\left[\delta \Pi_{\mathrm{i}}(\mathrm{t}) / \delta \Delta \mathrm{P}_{\mathrm{i}}(\mathrm{t})\right]$ is the marginal change in profits for a small change in price discount at date t. $\mathrm{H}_{1}$ is a positive coefficient. The story is that a seller starts with a price discount and then gropes for the best discount by changing the discount: he raises the discount at date $\mathrm{t}+1$ by a factor $\mathrm{H}_{1}$ if the discount at $\mathrm{t}$ increased his profits. He lowers the discount at date $t+1$ by the factor $\mathrm{H}_{1}$ if the discount at date decreased his profits. This type of dynamics has been studied in [8].

Assumption 4: We further assume the existence of symmetric Nash equilibrium. That is, at equilibrium

$\Delta \mathrm{P}_{\mathrm{i}}=\Delta \mathrm{P}_{\mathrm{j}}=\Delta \mathrm{P}$

Theorem 1: The price dynamics is then reduced to the following:

$\Delta \mathrm{P}(\mathrm{t}+1)=\lambda-\theta \Delta \mathrm{P}(\mathrm{t})+\gamma[\Delta \mathrm{P}(\mathrm{t})]^{2}$

Where:

$\lambda=\mathrm{H}_{1} \alpha \mathrm{P}^{\mathrm{D}}\left(\left(\beta_{2}-\beta^{1}\right), \gamma=2 \alpha \mathrm{H}_{1} \beta_{2}\right.$, $\theta=\mathrm{H}_{1}\left(\beta_{2}-\beta^{1}\right) \alpha+2 \alpha \mathrm{H}_{1} \beta_{2} \mathrm{P}_{\mathrm{D}^{-}}-1$

Proof: Differentiating (2a) with respect to $\Delta \mathrm{P}_{\mathrm{i}}$ and substituting it in (2b) and using (2c) yields (2d). QED.

Theorem 2: The dynamics as represented by (2a) has two fixed points:

$\Delta \mathrm{P}^{*}=\left[1+\theta+\operatorname{SQRT}\left\{(1+\theta)^{2}-4 \lambda \gamma\right\}\right] /[2 \gamma]$

$\Delta \mathrm{P}^{* *}=\left[1+\theta-\operatorname{SQRT}\left\{(1+\theta)^{2}-4 \lambda \gamma\right\}\right] /[2 \gamma]$ 
Both these equilibria are the steady state of the above dynamics. It is instructive to see that the first equilibrium given by (3a) is unstable. The second equilibrium given by (3b) is stable if :

$\operatorname{SQRT}\left\{(1+\theta)^{2}-4 \lambda \gamma\right\}<2$

Proof: Substituting $\Delta \mathrm{P}(\mathrm{t}+1)=\Delta \mathrm{P}(\mathrm{t})=\Delta \mathrm{P}$ into equation (2d) yields the quadratic equation whose two roots give the steady state of the above dynamics. Evaluating the slope of the equation (2d) for $\Delta \mathrm{P}^{*}$ and $\Delta \mathrm{P}^{* *}$ will give us the rest of the theorem. QED.

Theorem 3: It is now simple to rescale the variables to arrive at the following dynamics:

$\mathrm{X}_{\mathrm{t}+1}=\mathrm{B} \mathrm{X}_{\mathrm{t}}\left(1-\mathrm{X}_{\mathrm{t}}\right)$

Where:

$\mathrm{X}_{\mathrm{t}}=\gamma\left(\Delta \mathrm{P}^{*}-\Delta \mathrm{P}(\mathrm{t})\right) / \mathrm{B}$

$\mathrm{B}=1+\operatorname{SQRT}\left\{(1+\theta)^{2}-4 \lambda \gamma\right\}$

Equation (4a) is the much celebrated logistic equation expounded by May [9] and Feigenbaum [10]. From May [9] we know that chaotic behavior sets in for $\mathrm{B} \geq 3.57$.

Proof: The proof, being simple, is omitted. QED.

\section{DISCUSSION}

It is now possible to characterize the dynamics: for $1<\mathrm{B}<3$ the dynamics of price discounts converge to the stable equilibrium $\Delta \mathrm{P}^{* *}$. This is the region of stability that plays an important role in equilibrium analysis as discussed in Gangopadhyay [10]. If $\mathrm{B}$ is increased above $3, \Delta \mathrm{P}^{* *}$ becomes unstable and the price discounts converge to a stable 2-period cycle. As B is increased further the stable period cycles of $n$ bifurcates into cycles of period 2n. From Feigenbaum [9] we know that the range of A values for which the nth cycle is stable shrinks at a geometric rate. For $\mathrm{B}>3.57$ the price discounts evolve through a cycle of infinite period. The price discounts are within the relevant bounds but never repeat. For a higher order price discounts may look like a random process but these discounts are fully deterministic.

\section{CONCLUSION}

We consider price discounts in a dynamic context. Customer flows to a seller are influenced by secret prices and price discounts chosen by its rival. The demand function of each customer is linear and downward sloped in prices. Since price discounts are secret, an instantaneous Nash equilibrium is not arrived at. Sellers start off with initial price discounts and gradually update these discounts $t$ enhance their profits. We have shown that the dynamic path of price discounts will be characterized by chaotic behavior in the region of instability.

The finding has important bearings: it is typically assumed in the deductive equilibrium approach to modern economic theory that the Nash equilibrium dispels all systematic prediction errors and the economic system settles in an equilibrium characterized by selfconfirming and mutual-best responses. This approach has its most dominant influence on modern industrial economics, popularly known as industrial organization. The deductive equilibrium analysis has contributed to a better understanding of modern industrial economics. However, little attention has been given to the regions of instability. We established that the postulated price discount dynamics can exhibit chaotic behavior. Firms now fail to see systematic errors. Firms also fail to make long-run predictions with certainty even thought they act in a deterministic world. Time profiles of prices and quantities, which start very close together, will separate exponentially. The strength of Nash equilibria gets terribly emasculated. We conclude that an application of standard results of chaotic behavior can be a very important step forward to understand the dynamics of industrial economics.

\section{REFERENCES}

1. Bain, J. S., 1952. Price Theory. John Wiley and Sons. New York, pp: 420-440.

2. Gangopadhyay, P., 2000. Coase Theorem and Coalitional Stability: The Principle of Equal Relative Concession, Theory and Decision. Kluwer, 49: 179-189.

3. Shepherd, W. G., 1985. The Economics of Industrial Organization. ( ${ }^{\text {nd }}$ Edn.). Prentice Hall.

4. Gangopadhyay, P., 2002. Politics and Nature of Competition in Oligopolistic Markets. In A. Woodland (Ed.), Economic Theory and International Trade: Essays in Honour of Murray Kemp. Edward Elgar, pp: 236-243.

5. Gangopadhyay, P., 2004. Strategic Manipulation and Information Market Microstructure. Australian Economic Papers, Blackwell, 48: 41-57.

6. Stiglitz, J. E., 1987. Competition and Number of Firms in a Market: Are Duopolists More Competitive than Atomistic Competition? J. Political Econo., 95: 1041-1061.

7. Phelps, E. S. and S. J. Winter, 1970. Optimal Price Policy under Atomistic Competition. In E. S. Phelps (Ed.), Microeconomic Foundation of Employment and Inflation Theory. W.W. Norton, New York.

8. Gangopadhyay, P., 1997. Differential Profit Rates and Convergence to the Natural State. The Manchester School, Blackwell, LXV: 534-568.

9. May, R. M., 1976. Simple Mathematical Models with Very Complicated Dynamics. Nature, 261:459-467.

10. Feigenbaum, M.J., 1978. Quantitative Universality for a Class of Non-Linear Transformations. J. Stat. Phy., 19: 25-31. 